\title{
REMARKS: PANEL OF PROVOSTS
}

\author{
David E. Shulenburger \\ Provost \\ University of Kansas
}

Mike Crow's challenge to our three universities to find research niches is one I believe we must hear and heed. I think some of the discussion since Dr. Crow's initial presentation has missed the point. Some of us have heard in his words the suggestion that Midwestern universities will never be able to compete head-to-head with large universities on the coasts and therefore must adopt a niche strategy. Careful review of the full presentation, however, shows that he in fact has designed a niche strategy for Columbia University. What he is calling for is an institutional focus-one or two major ideas that can captivate and energize the communities so they become effective research machines.

Dr. Crow's statement about the criteria departments should use when selecting new colleagues struck me as eminently logical and, at the same time, unnervingly innovative. He said that departments, when selecting new colleagues, should use as a selection criterion the greatest potential value to other scholars at the university for purposes of pursuing the university's niche strategy. In my experience, when departments get the opportunity to select a new colleague, they tend to focus on their internal needs. These needs are seldom identified with respect to the university, but rather concentrate almost entirely on the department. Our German research university heritage shows most plainly here. Discipline is paramount. I certainly know of a number of cases where departments at our university essentially have refused to pursue aims clearly needed for the university to succeed. Ultimately, persuading departments to act in order to advance the aims of the institution is very difficult, but necessary if we are to succeed.

Why do departments focus inwardly instead of on the university? Let me suggest three possibilities:

1) Because the university has not identified niches that are known to departments. If this is the case, it is clearly our problem as administrators. It does no good to identify niches if they are not communicated to the public and justified.

2) Departments pursue their own aims simply because they don't care what niches the university has chosen. Again, the German university model would be supportive of this second possibility.

3) There is some truth in both hypotheses. As in most phenomena of social sciences, I think the answer has to be number 3-both of the explanations are correct. 
Richard Schowen receives the award at this conference for reinforcing my own prejudices about departments. In his brilliant discussion about centers versus departments, he essentially announced the thesis that centers function best for fostering interdisciplinary research while departments function best for pursuing educational ends. Dr. Schowen ended up finally waffling, suggesting that both the centers and departments have a purpose within the institution. I would like to focus just a little bit on departments and the disciplines that they house. Specifically, the word discipline has two meanings. The first, of course, has to do with the scholarly focus. The second has to do with discipline of thought. Clearly, it is important to the development of new scholars that they have this discipline of thought so that their work proceeds from an organized set of principles. Without this, it is hard to maintain that what we do is science.

Thus, while I accept Dr. Schowen's waffling-and the reason for his waffling-one has to recognize that there are enormous economic costs to maintaining parallel department and center structures at a university. For this reason, I have steadily pushed to reduce the number of departments at the University of Kansas so that those remaining would contain larger numbers of disciplines and have the critical mass to behave both like departments and centers.

In my six years as a chief academic officer, it has been this effort to reduce the number of units that has probably taken the greatest toll on me. Departments are academic homes to faculty members. Disrupting a department has the potential of disrupting the work of its members and threatening their security. Institutional costs are often a vague concept to a faculty member while the costs that are associated with change are quite real to the individual. Dr. Schowen described the merger over time of the biology-related departments at KU into a single entity. This, indeed, is a center-like unit that I now expect to do a wonderful job in both overseeing degree programs and generating interdisciplinary research. This migration, however laudatory, did not occur simply because its creation resulted in a more efficient and effective use of university resources. It occurred because Dean Sally Frost Mason and a few enlightened folks in the department really pushed for it to occur. I congratulate Dr. Frost Mason for that effort. I know it has been costly to her.

As I said earlier, the notion of selecting niches and enhancing the volume of research we do is attractive. However, one must not lose sight of our reason for making these adjustments. The purpose of each of our three universities is education. Notice that I did not say our purpose was teaching or our purpose was research-it is education. We were founded, and we have been funded, by our local legislatures so that we carry out that education. Victor Frost gave a presentation the other day on the tremendous success of his institute. I have had the opportunity to describe the success of that institute to Regents and others in recent days and invariably during the description, it becomes obvious that it would be impossible for the University of Kansas to train high level personnel for the telecommunications industry if Dr. Frost weren't doing the research that he is. The research that he does is essential to the training of masters and doctoral students who will eventually go into both universities and the telecommunications 
industry. Thus, a point I want to make-and make quite strongly-is that research is a byproduct of our universities. Research is not the main endeavor of our universities.

This is not at all to denigrate the role of research in our institutions. It is simply to make clear to us what the organizing principle of our activity has to be. That organizing principle has to be education. Were it not so, our support and funding by state legislatures would be threatened.

There is a tendency for centers to become focused on research instead of education as a goal, to create staffs comprised of post-doctoral fellows and adjuncts in an effort to accomplish as much research as possible. It is possible for an institute or center to forget that education is the goal of the institution in which it resides. Good, healthy centers, like the three represented here, have significant post-doc and adjunct staffing, but all have a very large component of doctoral and masters' students.

Thus, while it is important to increase the volume of externally funded research on our campuses, it is important to do so for the right reasons. If we attempt to outcompete private and non-profit research organizations by becoming like them, we succeed at our own peril. Such organizations don't need a core of humanities and social sciences undergirding their purposes. Such institutions never give tenure to their researchers. They don't because such add-ons and personnel practices add to costs without generating more product. Such add-ons and personnel practices are essential to our identities as universities; for us to adopt goals strictly to bring in more research dollars without concern about the continuation of the whole enterprise will produce, at best, a Pyrrhic victory.

Thus, what I am describing is really a question of balance. Clearly, our teaching is important, as is our research, but our primary end is education. We have to see both the research and the teaching that we do as contributing to that end.

Finally, Mike Crow's suggestion that research volume will continue to concentrate on the two coasts is worrisome to me. I don't think that this concentration is in our country's best interest. I agree fully with the argument that research should go to those universities where the intellectual capital is, but I also believe that researchers will go to those universities where the economic resources are. There is value in keeping a geographic spread of intellectual capital throughout this country. So long as we have two senators from each state, I don't believe the political process will permit a complete concentration of intellectual capital and research dollars on the two coasts.

Let me switch to another topic. As many of you know, in the past year I have been concerned and involved in national movements dealing with the cost of research literature. I am concerned about research literature because it is both an output of our research and educational activity and an input to it. In spite of everything that has been done in the past year, costs are still increasing at more than $10 \%$ per year-a rate far greater than any university's library budget is increasing on a sustained basis. The result is increased cancellation of journals and decimation of monograph collections so that we 
can maintain an ever smaller number of journals. This situation is clearly undesirable and threatens the success of our research and teaching missions.

Two major efforts are underway to deal with this cost increase. The first is sponsored by the American Research Library Association and goes under the acronym of SPARC. This is an attempt to form new electronic journals that will provide researchers with publishing outlets that will be affordable to their universities. Their first venture is a journal that is sponsored with the American Chemical Society. Other journals will follow. Dramatic cost reductions occur when one goes to web-based distribution of the material, and these cost reductions can be passed on directly to libraries and society members.

The second experiment is by a set of AAU academic officers. A bold plan is underway to separate the review of journal articles from the publication of those articles. It works as follows. The review mechanism is set up by a professional society and all manuscripts are submitted to the review board. The review board judges whether they are "good science." If the manuscripts so qualify, they are put on a web-site maintained by the association and accessible to all researchers and students. Journals are then free to go to the refereed manuscripts on the web site and select for publication those that best fit their journal. This separation of quality review from publication makes the articles available in the public domain for all to see, whether or not they are published. If this venture succeeds, the fact that articles are publicly available will have to cause journals to temper, and probably to roll back, price increases, since articles will be available at no cost. While there is an advantage to ultimate publication in a major journal, these journals would lose their ability to compel large price increases from the academic community.

There is very powerful criticism of the AAU academic officers' proposal. The criticism is that essentially a monopoly review board would be set up in each profession. These entities conceivably could reduce innovation and ultimately harm the professions. I hope that this criticism can be dealt with, and the review and web-publication idea be given a chance to work.

During the past year, anti-trust authorities in the European Union and the United States have begun to look at major publishers. A merger that would have hurt the academic enterprise has been stopped in Europe, and the attention of the U.S. Justice Department to a few large publishers will, I hope, begin to change their behavior in this country. But still we have costs going up by $10 \%$ a year.

Ultimately, I believe that simple economics will force electronic distribution to replace paper. We can't continue to subscribe to journals whose costs go up $10 \%$ per year; scholars will find a way around it. The physicists, I believe, already have achieved this end with their electronic preprints. I think the story that was in the Chronicle of Higher Education in early July, pointing out that a number of journals wouldn't accept articles that had been previously in electronic form on the web, is notable simply because so few journals wish to be identified publicly with that stance. 
While I believe that economics ultimately will win out, I would prefer that it be nudged along a little bit. My favorite nudging these days would be the creation of a system-perhaps at the Library of Congress-where all manuscripts accepted for publication by journals would be submitted and placed on the web within 30 days of their appearance in print. This system would have to be a mandatory one for faculty members at U.S. universities so that all articles would be placed there. Once placed on the web, articles would need to be accessible to anyone. I propose access in a somewhat unusual manner, say 15 cents per view. Let's give five cents to the journal, which would undoubtedly lose some subscriptions because its contents would be available (albeit with a lag) to the general public. Let's give another five cents to the Library of Congress to pay for the operation of the enormous web site, and let's return five cents to the author. The authors get nothing now. This scheme would make all research literature available at a fraction of the cost that we now pay. It also would produce other results. I imagine it would be somewhat humbling to the author who ultimately receives royalties amounting to 20 cents from the article, and it might well have the effect of stemming the publication of those works that are really not of interest to anyone, including the scientific community.

The movement of journals to an electronic medium is likely to have effects that are difficult to envision today. Ultimately, the cost is lower and the ability to do electronic searches will be enormously valuable, but we should heed individuals like Marshall McLuhan, who pointed out long ago that often the medium is the message. Research available in printed form is tactile, and appears to have permanence. We have all grown to love paper, books in particular. It is a little more difficult to love an electronic version and a little more difficult to treat it as permanent. I suspect having research in that form will have advantages and subtle psychological disadvantages. I am not about to call for restricting research to paper because the economics of that are lousy. But we should not go into this major change without recognizing that it will have significant ramifications on many levels. 